Revista Destaques Acadêmicos, Lajeado, v. 10, n. 3, 2018. ISSN 2176-3070

DOI: http://dx.doi.org/10.22410/issn.2176-3070.v10i3a2018.1969

http://www.univates.br/revistas

\title{
DIÁLOGOS EDUCATIVOS COM JOVENS ESCOLARES SOBRE O USO DE ANABOLIZANTES DEBATIDOS VIA WEB RÁDIO
}

\author{
Raimundo Augusto Martins Torres ${ }^{1}$, Karlla da Conceição Bezerra Brito Veras ${ }^{2}$, \\ Leidy Dayane Paiva de Abreu ${ }^{3}$, Aretha Feitosa de Araújo ${ }^{4}$, \\ Ana Clarissa Azevedo de Sousa ${ }^{5}$, Mayra Aparecida Mendes Ribeiro ${ }^{6}$, \\ Isabela Gonçalves Costa ${ }^{7}$
}

Resumo: O uso de Esteroides Anabolizantes vem crescendo bastante nos últimos anos, e não apenas por atletas na busca de um bom desempenho, mas também por jovens que procuram boa aparência física. Desta forma, há necessidade de maiores informações sobre o uso de Esteroides Anabolizantes na juventude. Nessa perspectiva, foi aliado o uso destas tecnologias à educação e saúde, surgindo assim a Web Radio AJIR (Associação de Jovens de Irajá), que é uma estratégia que visa difundir informação e conhecimento através do meio digital. Um dos programas veiculados na Web Rádio Ajir é o Programa Em Sintonia com a Saúde, desenvolvido num estúdio-sala na Universidade Estadual do Ceará (UECE), em Fortaleza, Ceará. Assim, o estudo trata-se de uma pesquisa -

1 Enfermeiro. Professor Doutor da Universidade Estadual do Ceará (UECE). Fortaleza- CE. Brasil. E-mail: augustomtorres70@gmail.com

2 Enfermeira. Mestre em Ensino na Saúde pela Universidade Estadual do Ceará (UECE). Fortaleza- CE. Brasil. Fortaleza- CE. Brasil. E-mail: karlla_veras@hotmail.com

3 Enfermeira. Doutoranda do Programa de Pós- Graduação de Cuidados Clínicos em Enfermagem e Saúde. Fortaleza- CE. Brasil. E-mail: dayannepaiva@hotmail.com

4 Enfermeira. Doutoranda do Programa de Pós- Graduação de Cuidados Clínicos em Enfermagem e Saúde. Fortaleza- CE. Brasil. E-mail: aretha.feitosa@gmail.com

5 Enfermeira. Coordenadora e Professora do Curso Técnico em Enfermagem na Escola Estadual de Educação Profissional do município de Sobral- CE. Brasil. E-mail: anaclarissa_azevedo@yahoo.com.br

6 Enfermeira. Coordenadora e Professora do Curso Técnico em Enfermagem na Escola Estadual de Educação Profissional do município de Ubajara- CE. Brasil. E-mail: aryam_ribeiro@hotmail.com

7 Graduanda em Enfermagem pela Universidade Estadual do Ceará (UECE). E-mail: isabelauece@gmail.com 
interventiva, que descreve as ações de intervenção de um profissional de saúde, junto a 40 jovens escolares de uma escola pública do município de Sobral, Ceará, por meio do projeto de extensão "Em Sintonia com a Saúde" veiculada pela Web Rádio AJIR. Assim, o início da interação entre os jovens escolares e entrevistado/ convidado ocorreu ao acessar o site da web rádio, por meio do link: www.ajir.com.br. A partir das perguntas elaboradas pelos participantes, foi possível perceber que existiam muitas dúvidas dos jovens acerca dos efeitos colaterais e problemas na saúde com o uso de anabolizantes; complicações e alterações no organismo das mulheres que utilizam anabolizantes e dependência dos anabolizantes. Conclui-se, que a interação entre jovens escolares através de uma Tecnologia Digital de Informação e Comunicação (TDIC), como a Web Rádio Ajir trouxe contribuições para o aumento dos conhecimentos dos jovens sobre os riscos e efeitos colaterais do uso de anabolizantes, visto que os mesmos adotarão posturas reflexivas em relação ao uso de anabolizantes.

Palavras-chave: Tecnologia; Educação em Saúde; Anabolizantes.

\section{INTRODUÇÃO}

O uso de Esteroides Anabolizantes vem crescendo bastante nos últimos anos, e não apenas por atletas na busca de um bom desempenho, mas também por jovens que procuram boa aparência física, muitas vezes influenciados pela mídia e por não estarem satisfeitos com o seu corpo. Porém o apelo ao corpo sedutor atraem os jovens que trocam uma saudável atividade física, por ciclos de anabolizantes, e a falta de informações sobre os efeitos, a consciência de que não existe maneira segura para utilização de Esteroides Anabolizantes, excedo o uso terapêutico (LIMA; SANTOS, 2009).

No público adolescente, investigações recentes apontam para um assíduo e crescente aumento do consumo de anabolizantes, cuja finalidade não é competitiva, mas sim atingir um corpo "belo" e considerado "ideal". Essa visão tem sido cada vez mais influenciada pela supervalorização dos corpos em sociedades de consumo pós-industriais e do imediatismo por elas propagado (OLIVEIRA, 2012).

Nesse contexto, no organismo humano o aumento muscular, principalmente nos tecidos musculares e ósseos é promovido pelos esteroides anabolizantes um grupo de hormônios esteroides naturais - que são sintetizados - por combinações variadas de suas propriedades, dependendo do efeito que se deseja ter sobre o corpo (LIMA \& SANTOS, 2009).

Assim, a atividade física vem sendo considerada como um dos meios mais eficientes de promoção à saúde, fazendo com que cada vez mais jovens e adultos busquem academias de ginástica e centros esportivos com o propósito de alcançarem o corpo ideal. Entretanto, a musculação ou outras atividades físicas não desenvolvem os músculos de forma rápida. Assim, em busca do corpo ideal, muitos jovens e adolescentes usam os esteroides anabolizantes androgênicos (EAA) de forma indiscriminada e sem a mínima orientação, o que 
está se tornando um problema para a saúde devido aos riscos que os usuários são expostos (IRIART et al., 2009).

Desta forma, há a necessidade de maiores informações sobre o uso de esteroides anabolizantes na juventude, intervenções a nível educativas no âmbito maior, como nas escolas, assim como é importante à intervenção dos profissionais da área de saúde que lidam diariamente com jovens, alertando sobre a prática do esporte, sua importância na adolescência, pois a juventude de certa forma desconhecem que há um limite genético para o desenvolvimento muscular, que depende de atividade física ordenada e supervisionada, repouso e alimentação orientada e adequada.

Desse modo, foi escolhido o ambiente escolar como foco para ser aplicado uma intervenção utilizando uma tecnologia educacional. Nessa perspectiva, foi aliado o uso destas tecnologias à educação e saúde, surgindo assim a Web Radio AJIR (Associação de Jovens de Irajá), que é uma estratégia que visa difundir informação e conhecimento através do meio digital, atuando na comunicação e educação em saúde através da transmissão de uma programação diversificada com temas sobre saúde para os jovens, como a discussão do tema "O uso de anabolizantes".

Nesse sentido, a utilização desses recursos tecnológicos de comunicação e informação vem se tornando mais frequentes devido à atratividade e facilidade de comunicação e acesso, e, por conseguinte, modificando a maneira como as pessoas se relacionam, aprendem e se comunicam, especialmente entre a população jovem (SANTOS, 2014).

Assim, um dos programas veiculados na Web Rádio Ajir é o Programa Em Sintonia com a Saúde (S@S), desenvolvido num estúdio-sala na Universidade Estadual do Ceará (UECE), em Fortaleza, Ceará, com programas semanais ao vivo e/ou gravados, disponibilizados no site da Web Rádio AJIR para posterior consulta pela internet: http://www.ajir.com.br/

O Programa Em Sintonia com a Saúde é produzido em sala estúdio, onde professores e estudantes de cursos de graduações na área da saúde trazem semanalmente, especialistas e representantes da sociedade civil para interagir com as juventudes escolares. Os debates expandem-se para bate-papo por meio dos canais apensados ao site, como Facebook, twiter, whatsApp, Skype e Mural de recados que permite a participação ao vivo de jovens escolares do ensino fundamental e médio de escolas públicas do Ceará e de outras cidades do Brasil.

O material produzido durante a transmissão do programa é editado e postado em um blog para acesso coletivo: www.saudeuece.ajir.com.br. Na grade de programação da emissora é garantido às reprises das entrevistas realizadas na semana. As dúvidas e inquietações dos participantes são discutidas através dos canais de acesso ao site da emissora digital. 
Dessa forma, tendo em vista a importância das Tecnologias Digitais de Informação e Comunicação (TDIC's), para reduzir as vulnerabilidades dos jovens, o estudo apresentou as seguintes questões norteadoras: quais os conhecimentos dos jovens de uma escola pública do Ceará sobre o uso de anabolizantes? Quais são suas principais dúvidas sobre esse tema?

Existe uma grande carência de informações a nível pedagógico dos reais efeitos colaterais causados pelo uso abusivo de esteroides anabolizantes e energéticos na adolescência, havendo assim a necessidade da abordagem dessa problemática no ambiente escolar, pois essa é uma das formas de levar conhecimento aos jovens visando que estes se previnam e evitem tais problemas (MURER, OLIVEIRA \& MENDES, 2009).

Desse modo, o estudo possui como objetivo descrever a intervenção de um profissional de saúde com o uso de uma tecnologia digital denominada Web Rádio AJIR, utilizada como mecanismo de comunicação dialógica para o cuidado em saúde entre jovens escolares, onde foi abordado o tema "Saúde do corpo humano: o uso de anabolizantes".

Nesse sentido, a investigação contribuirá e permitirá melhorias nas medidas de promoção à saúde e prevenção ao uso de anabolizantes pelos jovens. O estudo possibilitará a produção de novas pesquisas sobre as TDCI's no processo de educação em saúde, de modo a constituírem-se espaços mais integralizados, construtivos e democráticos.

\section{MÉTODO}

O estudo trata-se de uma pesquisa - interventiva, que descreve as ações de intervenção de uma enfermeira junto a 40 jovens escolares de uma escola pública do município de Sobral, Ceará, por meio do projeto de extensão "Em Sintonia com a Saúde" veiculada pela Web Rádio AJIR. O projeto teve como objetivo trabalhar com a transferência de tecnologia do cuidado em saúde com os jovens nas escolas do estado do Ceará por meio da interação no referido canal de comunicação.

Desta forma, a pesquisa-intervenção consiste em uma tendência das pesquisas participativas que buscam investigar a vida de coletividades na sua diversidade qualitativa, assumindo uma intervenção de caráter socioanalítico. Esse tipo de pesquisa apresenta passos metodológicos próprios que iniciam com o diagnóstico, plano de intervenção e execução e avaliação (ROCHA, 2003).

Assim, a Web Rádio é um canal de comunicação digital articulada entre a Associação dos Jovens de Irajá - AJIR com o Laboratório de Práticas Coletivas em Saúde - LAPRACS/CCS da Universidade Estadual do Ceará- UECE, com apoio da Pró- Reitoria de Extensão - PROEX. O programa é veiculado, mantendo o seu cronograma de execução anual, semanalmente, ao vivo, nas quartas-feiras no horário de $16 \mathrm{~h}$ às $17 \mathrm{~h}$, tendo como sede de transmissão uma sala-estúdio na UECE, em Fortaleza, com abrangências intermunicipais, para os 
diversos lugares, onde as escolas se conectam e atuam juntamente aos debates sobre questões de educação e de saúde.

Desse modo, para esse estudo foi realizado a discussão com os jovens sobre o tema "Saúde do corpo humano: o uso de anabolizantes", que ocorreu no dia 20 de junho de 2018, veiculado pelo programa "Em Sintonia com Saúde - S@S" através da Web Rádio AJIR. Os sujeitos do estudo foram estudantes do primeiro ano científico, de uma escola estadual de educação profissional, do município de Sobral- Ceará.

O critério para a seleção do local foi baseado pelo fato do diretor e profissionais da escola manifestarem interesse em desenvolver o projeto de extensão "Em Sintonia com a Saúde", onde foi assinado pelo diretor escolar um termo de consentimento livre e esclarecido, oficializando o desenvolvimento das ações do projeto de extensão na instituição.

A participação dos jovens na pesquisa foi definida após atender os seguintes critérios de inclusão: jovens na faixa etária entre 15 e 16 anos, que aceitaram participar voluntariamente do estudo, estavam regularmente matriculados e frequentando a escola, se interessaram pela temática abordada no programa e que assinaram os TCLE. Os critérios de exclusão foram caracterizados pelos estudantes que não participaram do programa por falta de interesse na temática ou por ausência na escola e não assinatura do TCLE. A coleta dos dados envolveu a observação participante da enfermeira, com visita de campo a escola, pesquisas em ambientes virtuais e arquivos de áudio e vídeo da web rádio AJIR.

Foi realizado um esclarecimento quanto aos objetivos, métodos, benefícios previstos ou potenciais riscos da pesquisa para os jovens. Como também foi garantido o anonimato dos participantes do programa, garantindo assim o sigilo ético da pesquisa. Os riscos que esta pesquisa causou diz respeito tanto à participação dos jovens escolares no programa em Sintonia com a Saúde da Web Rádio AJIR, quanto à identificação no momento da análise e divulgação dos resultados. Contudo, os participantes estavam cientes e concordaram com a participação no programa. Portanto, todo e qualquer risco foi evitado ao máximo.

Para o anonimato dos jovens, foram utilizados os codinomes Jovem 1, Jovem 2, Jovem 3, até Jovem 18. Para análise dos dados, utilizou-se a categorização das falas de Minayo, com a seguinte categoria: Dialogando sobre o uso de anabolizantes com jovens escolares via web rádio.

Como procedimentos éticos a pesquisa adotou a Resolução $n^{\circ} 466 / 12$ do Conselho Nacional de Saúde (CNS), que garante proteção aos seres humanos participantes de pesquisas científicas respeitando sua dignidade. Desta forma, a pesquisa teve início após a aprovação do projeto pelo Comitê de Ética em Pesquisa da Universidade Estadual do Ceará, onde a vivência fez parte de uma pesquisa maior "uso da Web Rádio na formação e no cuidado em saúde: 
experimentando estratégias de comunicação e educação em saúde com as juventudes" submetida ao Comitê de Ética e Pesquisa (CEP) da UECE. Parecer $\mathrm{n}^{\mathrm{o}}: 1.761 .115$.

\section{RESULTADOS E DISCUSSÃO}

Dialogando sobre o uso de anabolizantes com jovens escolares via web rádio.

O início da interação entre os jovens escolares e entrevistado/ convidado ocorreu ao acessar o site da web rádio, por meio do link: www.ajir. com.br e pelos demais canais de acesso tais como: twitter (@radioajir), Skype (Skype 01: web rádio ajir), Skype 02 (radioajir), Facebook (Web Rádio AJIR) e Mural de Recados do site e blog (www.saudeuece.ajir.com.br). Essa interação entre alunos e profissionais especialistas (convidados) aconteceu através da elaboração de perguntas, tira dúvidas e, sobretudo, produção de conhecimento (TORRES, 2015).

Para tornar a transmissão mais dinâmica e interativa, foi utilizada uma Web TV agregada ao site da web rádio, que no momento do programa ao vivo emitiu a imagem do locutor e debatedor convidado, assim como os vídeos culturais e outras imagens agregadas ao tema debatido no programa realizado no canal.

Assim, os jovens participantes do programa foram estimulados a enviarem perguntas/comentários por meio de um software de comunicação e as atividades iniciaram com uma pergunta chamada de âncora, na qual foi realizada pelo facilitador do programa. Nessa perspectiva, a pergunta-âncora foi uma indagação desenvolvida pela equipe responsável pelo programa em sintonia com a saúde, que se referiu à temática abordada no dia, no caso "Saúde do corpo humano: o uso de anabolizantes". Tratou-se de uma espécie de provocação para que os estudantes pudessem pesquisar sobre o tema, envolver-se mais com o programa e concorrer a prêmios fornecidos pela equipe.

A pergunta âncora lançada no programa pelo facilitador do programa, foi: “O que são anabolizantes?". Dos 40 estudantes participantes do programa, 32 jovens responderam a pergunta âncora. Segue na tabela abaixo algumas respostas dos estudantes sobre a pergunta âncora. 
Tabela 01: Respostas de alguns jovens sobre a pergunta âncora lançada: 'O que são anabolizantes?'. A pergunta foi realizada pelo facilitador do programa 'Em Sintonia com a Saúde', transmitido pela Web Rádio AJIR, Fortaleza, CE, 2018.

\begin{tabular}{|c|}
\hline Pergunta Âncora: O que são anabolizantes? \\
\hline $\begin{array}{l}\text { Jovem 01: "São estimulantes que irão agir junto aos hormônios, fazendo que a massa muscular } \\
\text { cresça de maneira inadequada". }\end{array}$ \\
\hline Jovem 02: "São substâncias que contribuem para o aumento significativo da massa muscular". \\
\hline $\begin{array}{l}\text { Jovem 03: "É um tipo de hormônio que estimula o crescimento de vários tipos de tecidos, } \\
\text { principalmente os músculos". }\end{array}$ \\
\hline $\begin{array}{l}\text { Jovem 04: "São substâncias, que quando introduzidas no músculo do corpo humano, através } \\
\text { de injeção, causa o aumento do músculo". }\end{array}$ \\
\hline $\begin{array}{l}\text { Jovem 05: "É uma classe de hormônios esteroides naturais e sintéticos que promovem } \\
\text { o crescimento celular e a sua divisão de desenvolvimento de tecido como o muscular. São } \\
\text { substâncias derivadas do hormônio sexual masculino, a testosterona". }\end{array}$ \\
\hline $\begin{array}{l}\text { Jovem 06: "São substâncias que estimulam drasticamente o aumento da testosterona no corpo } \\
\text { do indivíduo, tendo como principal fator o aumento dos músculos no corpo do mesmo". }\end{array}$ \\
\hline $\begin{array}{l}\text { Jovem 07: "São drogas fabricadas para substituir o hormônio masculino, a testosterona. Eles } \\
\text { ajudam no crescimento dos músculos e no desenvolvimento das características sexuais". }\end{array}$ \\
\hline
\end{tabular}

Fonte: Arquivos do mural de recados do site da Web Rádio, Skype, WhatsaApp, Twitter, Facebook Messenger da página do Facebook: Web Rádio Ajir, 2018.

Esteroides anabolizantes é um tema comum nas rodas de conversas entre os adolescentes. Destarte, a escola torna-se responsável por colocar em pauta este tema, de modo a preparar um espaço onde professores e alunos compartilhem conhecimento e possam por meio do trabalho de sensibilização desenvolver uma consciência crítica sobre os efeitos que os esteroides podem causar sobre o organismo humano (OSORIO, 2011).

Nessa perspectiva, um fator reforçador para o uso de anabolizantes e que se relaciona com a concepção dos adolescentes sobre os anabolizantes, refere-se ao senso de urgência da adolescência, isto é, da pressa como característica típica dessa fase, proveniente das repentinas mudanças físicas, sociais e psicológicas experimentadas por eles e, que acabam resvalando em suas escolhas e tendo implicações significativas na saúde do adolescente (OLIVEIRA, 2012; RIBEIRO, 2001).

Desta maneira, após o lançamento da pergunta âncora para os jovens participantes do programa, teve início o debate que foi conduzido por um especialista sobre a temática, e nesta fase foi abordado uma breve explanação com alguns pontos chaves sobre o assunto, como: O que são anabolizantes, indicação, tipos e efeitos colaterais do uso dos anabolizantes, casos de indicação pelo médico e discussão sobre o uso terapêutico. 
Durante o programa, os jovens também foram estimulados a enviarem perguntas para o convidado especialista sobre o tema, para assim tirarem suas principais dúvidas. Assim, durante a transmissão do programa 18 jovens realizaram perguntas sobre o uso de anabolizantes. Segue abaixo na tabela 02, as perguntas realizadas pelos jovens.

Tabela 02 - Apresentação das perguntas realizadas pelos jovens sobre o tema "O uso de Anabolizantes", durante o Programa em Sintonia com a Saúde, transmitido através da Web Rádio Ajir, Fortaleza, Ceará, 2018.

\section{Perguntas dos jovens sobre o tema "Saúde do Corpo Humano: O uso de Anabolizantes".}

Jovem 01: "Quais os tipos de problemas que os anabolizantes podem trazer para a saúde dos adolescentes?".

Jovem 02: "Quais os efeitos colaterais do uso inadequado dos anabolizantes?".

Jovem 03: "O uso de anabolizantes pode afetar a saúde humana?".

Jovem 04: "Têm idade para usar o anabolizante? Ele pode ser considerado um tipo de veneno ou um tipo de remédio?".

Jovem 05: "Considerando que o uso de anabolizantes pode trazer doenças, por que ainda são vendidos legalmente no mercado?".

Jovem 06: "Quais as consequências que o uso dos anabolizantes podem acarretar para as pessoas?".

Jovem 07: "Em quais órgãos vitais os anabolizantes podem prejudicar mais?".

Jovem 08: “O que acontece se a mulher durante a gestação fizer o uso de anabolizantes?".

Jovem 09: "Nas mulheres que fazem o uso de anabolizantes, quais complicações podem ocorrer?".

Jovem 10: "O uso do anabolizante causa algum tipo de doença? E como ter o controle do uso?".

Jovem 11: "Usar anabolizantes é crime? O que fazer quando lhe oferecerem?".

Jovem 12: "Em mulheres que fazem o uso de anabolizantes, porque a menstruação fica desregular?".

Jovem 13: "Os anabolizantes podem atrapalhar no homem o desempenho sexual?".

Jovem 14: "Os anabolizantes podem causar algum tipo de paralisia?".

Jovem 15: "O uso exacerbado de anabolizante pode levar a morte?".

Jovem 16: "Para a compra de anabolizante necessita de prescrição médica? Como ele é disponibilizado pela assistência farmacêutica?".

Jovem 17: "As pessoas podem ficar dependentes dos anabolizantes?".

Jovem 18: "O que é melhor a se fazer para manter um corpo perfeito evitando qualquer tipo de anabolizantes esteroides?".

Fonte: Arquivos do mural de recados do site da Web Rádio, Skype, WhatsaApp, Twitter, Facebook Messenger da página do Facebook: Web Rádio Ajir, 2018. 
No senso comum, principalmente entre os jovens, percebe-se que normalmente os anabolizantes são vinculados aos padrões de perfeição, até porque, o seu efeito anabólico corresponde à propriedade da testosterona em proporcionar um aumento da massa muscular (IRIART et al., 2009).

Sobre os efeitos colaterais, a literatura informa que o câncer e a impotência sexual são os mais conhecidos, explicando que a possível causa se deve à mídia, por se utilizar do sensacionalismo e divulgar as consequências consideradas mais graves (RIBEIRO, 2001).

Desta forma, foi percebido durante o debate sobre a temática, uma forte e interessante interação entre jovens escolares e o convidado entrevistado do programa, visto que as perguntas dos alunos foram respondidas espontaneamente, de forma direta e esclarecedora no mesmo momento da transmissão do programa.

Desta forma, a partir das perguntas elaboradas pelos participantes, foi possível perceber que existiam muitas dúvidas dos jovens acerca dos efeitos colaterais e problemas na saúde com o uso de anabolizantes; complicações e alterações no organismo das mulheres que utilizam anabolizantes e dependência dos anabolizantes.

Assim, na análise das perguntas realizadas pelos estudantes, foi possível compreender que os jovens veem na Web Rádio um meio para esclarecer dúvidas que muitas vezes passam despercebidas no dia-a-dia e na sua convivência familiar. O esclarecimento das principais dúvidas sobre o uso de anabolizantes pelos jovens resultou em uma melhor compreensão dos inúmeros efeitos colaterais, pois jovens que fazem uso dos anabolizantes sem ter conhecimento ou orientação dos riscos e dos efeitos colaterais que eles provocam, podem ficar com sequelas ou chegar até ao óbito.

Dessa maneira, vê-se pelas falas entre jovens escolares e entrevistado convidado do programa que o debate fluiu espontaneamente, tornando o ambiente virtual acolhedor às demandas juvenis e tornando-o um potente espaço promotor de saúde.

Desta forma, as TDIC's favorecem a ampliação da interatividade através do emprego de ferramentas como imagens, textos, hipertextos, questionários, vídeos, áudios e jogos, que englobam as tecnologias da informática e da telecomunicação, mudando a linguagem de modo a torná-la multimídia (LOPES; PEREIRA; SILVA, 2013).

Apesar de se acreditar que existe a possibilidade do uso excessivo da tecnologia por parte dos jovens, defende-se a hipótese de que também existe o uso saudável e produtivo para seu crescimento intelectual, social e psicológico. Dessa forma, o relacionamento dos jovens com a tecnologia pode ser considerado fator importante para a saúde e o desenvolvimento (SANTOS et al., 2017, p. 102). 
Foi constatado, também, durante a transmissão do Programa em Sintonia com a Saúde através da Web Rádio Ajir, que o canal apresentou um poder de mobilização, provocação de discussões, ocorrendo à troca mútua de conhecimentos, pois durante o programa todos os estudantes de todas as escolas das cinco cidades, participam ao mesmo tempo do programa. Onde todos têm acesso às dúvidas e discussões dos jovens das outras escolas.

Portanto, torna-se um desafio não transformar as atividades educativas em meras práticas de educação em saúde pontuais, mas que de fato possa suscitar a elaboração de estratégias que promovam a participação do sujeito social e comunidades sobre a vida e a melhoria da qualidade de vida.

Nesse contexto, a emissora digital na Internet, é um recurso que se insere em novos arranjos para implementação de ações que visam à promoção da saúde em uma dimensão mais dialógica, interativa e rica de novos saberes através dos entornos da vida cotidiana dos jovens na escola e comunidade, superando o modelo tradicional para o foco da coprodução de saberes e autonomia de jovens (TORRES et al., 2015).

Nessa conjuntura, mostra-se fundamental combinar informação e comunicação à discussão e orientação, no sentido de proporcionar à juventude maior esclarecimento quanto a suas dúvidas, seus receios e seus tabus relativos ao tema para, assim, abrir espaço à busca de informações e ao interesse em prevenir possíveis agravos relacionados ao uso de anabolizantes. Assim, é importante ressaltar que as utilizações das TDIC's são essenciais para o desenvolvimento de atividades de cuidado, como a educação em saúde e a comunicação para promoção da saúde.

\section{CONCLUSÃO}

A web rádio, como exemplo de Tecnologia Digital da Informação e Comunicação, é uma ferramenta importante e complementar à discussão, problematização e construção de saberes dos jovens sobre o uso de anabolizantes, onde se mostrou como uma forma de quebra barreiras, favorecendo a discussão acerca dessa temática, que não possui visibilidade e prioridade pedagógica na formação dos estudantes.

Nessa perspectiva, considera-se que a comunicação produzida pelo Programa em Sintonia com a Saúde, transmitido via web rádio, foi de suma importância para auxiliar nas dúvidas presentes nos estudantes sobre o uso de anabolizantes, visando à disseminação das informações, onde deu oportunidades aos jovens de dialogarem com outras pessoas de forma online e inovadora.

Portanto, a interação entre jovens escolares através de uma TDIC, como a web rádio, trouxe valiosas contribuições para o aumento dos conhecimentos desses sobre os riscos e efeitos colaterais do uso de anabolizantes, visto que 
os mesmos adotarão posturas reflexivas, pois agora já conhecem os problemas que estas substâncias poderão causar em seu organismo.

\section{REFERÊNCIAS}

. Conselho Nacional de Saúde. Ministério da Saúde. Resolução 466, de 12 de Dezembro de 2012. 2012b. Disponível em: http:/ / conselho.saude.gov.br/ resolucoes/2012/reso466.pdf Acesso em: 23 jul. 2018.

IRIART, J. A. B.; ANDRADE, T. M. Musculação uso de esteroides anabolizantes e percepção de risco entre jovens fisiculturistas de um bairro popular de Salvador, Bahia, Brasil. Cad. Saúde Pública, São Paulo, v. 18, n. 5, p.1379-1387, 2002. Disponível em: . Acesso em: 19 agost. 2018.

LIMA, O. D. M. de; SANTOS Azenildo Moura. Importância da informação sobre o abuso do uso de esteróides anabolizantes andrógenos na adolescência. Revista Digital, ano 14, n. 134, jul. 2009. Acesso em: 30 de agosto de 2018.

LOPES, R. T.; PEREIRA, A. C; SILVA, M. A. D. O uso das TIC no ensino da morfologia nos cursos de saúde do Rio Grande do Norte. Rev. bras. educ. med., v. 37, n. 3, p. 359364, Set. 2013.

MINAYO, M.C.S. O Desafio do Conhecimento: Pesquisa Qualitativa em Saúde. 10. ed. São Paulo: HUCITEC, 2007, 406p.

OLIVEIRA, U. (2012). O uso de esteroides androgênicos anabolizantes entre adolescentes e sua relação com a prática da musculação (Tese de doutorado, Universidade de Campinas, SP, Brasil). Recuperado em http://www.unicamp.br/ unicamp/sites/default/files/jornal/paginas/ju_559_paginacor_09_web.pdf

OSORIO, Luis Felipe Baumotte. Os Esteróides Anabolizantes e a Sociedade. Brasília, 2011.

RIBEIRO, P. C. P. (2001). O uso indevido de substâncias: Esteróides anabolizantes e energéticos. Adolescência Latinoamericana, 2(2),97-101.

ROCHA, M. L; AGUIAR, K. F. Pesquisa-intervenção e a produção de novas análises. Psicol. Cienc. v.23 n.4 Brasília, 2003.

SANTOS, V. L. C.; SANTOS, J. E. As redes sociais digitais e sua influência na sociedade e educação contemporâneas. HOLOS, v. 6, p. 1-22, 2014.

SANTOS, André Luiz Lira et al. Cibercultura e jovens: um diálogo a partir da Psicologia. Revista Mangaio Acadêmico, João Pessoa, v. 2, n. 3, p.101-106, 2017. Disponível em: http://revistaadmmade.estacio.br/index.php/mangaio/article/ view/4478. Acesso em: 17 jan. 2018.

TORRES, R. A. M. et al. Comunicação em saúde: uso de uma web-rádio com escolares. Journal of Health Informatics, v. 7, n. 2, 2015. 